\title{
Dr. Francisco Vilardell Viñas (QEPD) († Enero 2021)
}

\section{Roque Sáenz ${ }^{1}$}

Dr. Francisco Villardell Viñas (RIP)

Hace unos días nos ha dejado uno de los Gastroenterólogos más prominentes, que dejó una labor digna de reconocimiento por su entrega por el desarrollo, avances y docencia de la especialidad.

Hijo y nieto de médicos. Su formación en torno a Henry L. Bockus, U. de Pensilvania, US, (195962) en los albores de la especialidad, su labor en la Organización Mundial de Gastroenterología (OMGE luego WGO) que presidió con gran éxito(1989-95), de la formación y desarrollo de la Escuela de Patología Digestiva de la U. Autónoma de Barcelona, en el Hospital de la Santa Cruz y San Pablo de Barcelona, (Director desde 1967-1996) donde recibió con generosidad a numerosos becarios de diferentes latitudes y en especial de Latino América, presidió la Societé Europeénne de Endoscopie Digestive (1970-74), además de publicaciones en el área de la Citología y endoscopia digestiva, de la cual publicó la Historia de la Endoscopia Digestiva en el Cincuentenario de la OMED (luego WEO), aparecen como hitos en su vida.

Su mayor recuerdo de la vida profesional es haber sido distinguido para cooperar en la recuperación de la Salud de SS. Juan Pablo II luego del atentado terrorista sufrido.

Hombre amable, culto, discreto, mesurado, sabio, elegante respetado y devoto. Se distingue sin hacerse notar. Su voz y pensamiento era escuchado y esperado en los ámbitos internacionales de la especialidad. Estableció una enorme red de especialistas expertos relacionados con su Escuela, la cual recibía a líderes del mundo en su servicio y en especial en el Curso Anual de la Especialidad de la Escuela.

Trabajó además en el Ministerio de Sanidad de España, dejando su impronta. (MIR) Cultor de la Opera

${ }^{1}$ Gastroenterología, Clínica Alemana, Vitacura. Santiago, Chile.

Recibido: 10 de enero de 2021

Aceptado: 11 de enero de 2021

\section{Correspondencia a:}

Dr. Roque Sáenz

Departamento de Gastroenterología Clínica Alemana Av. Manquehue Norte 1410, 4to piso, Vitacura, Santiago, Chile

rsaenz@alemana.cl
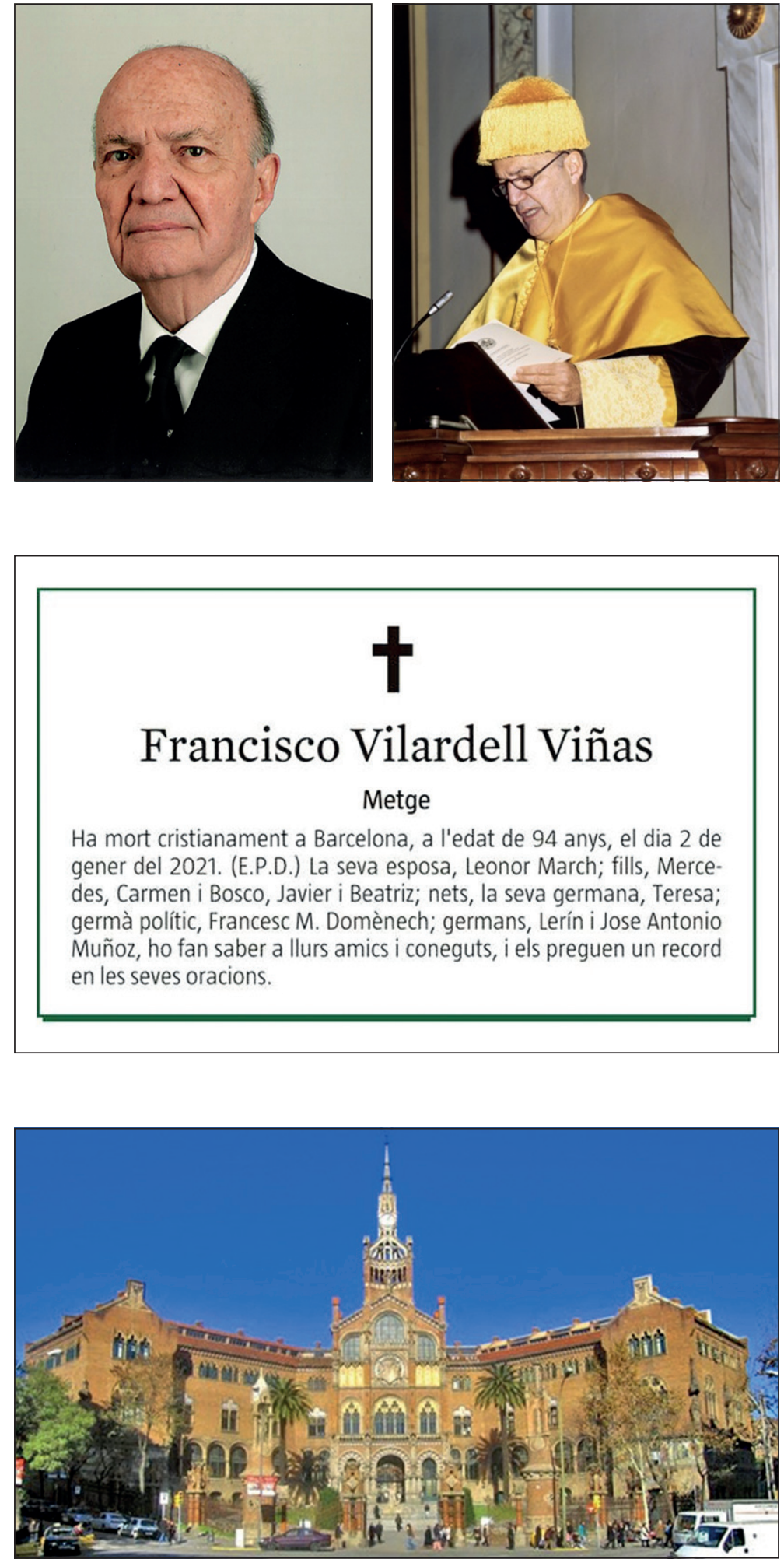

Hospital de la Santa Creu i Sant Pau- Barcelona. 


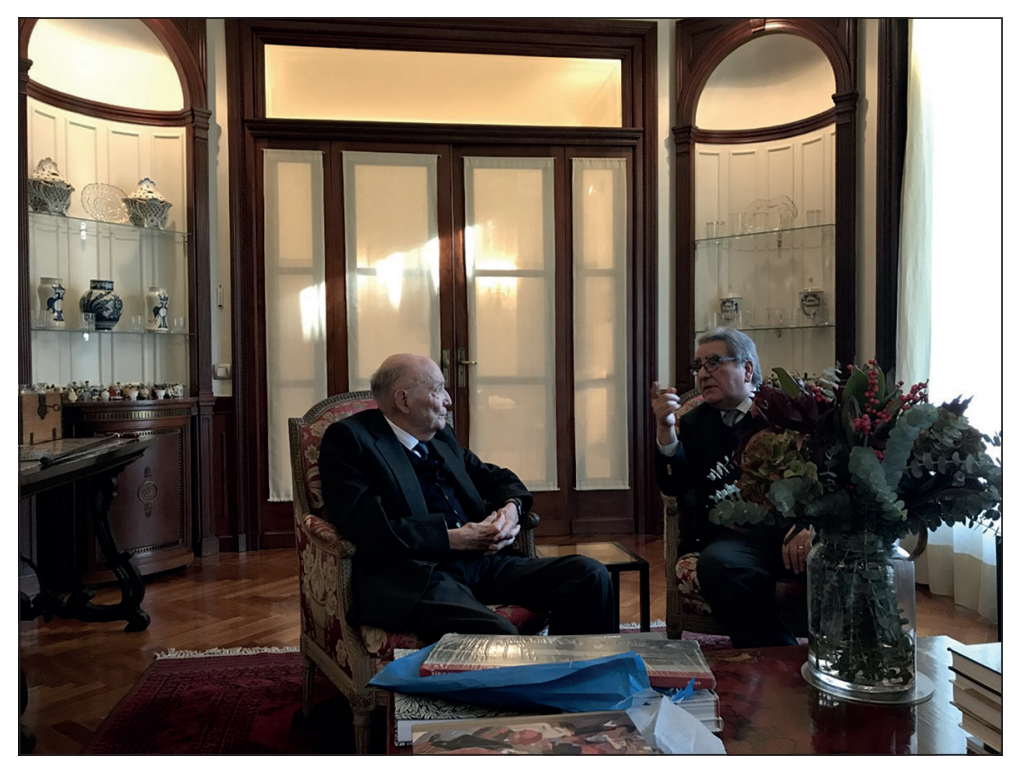

Prof. Francesc Vilardell Barcelona. Noviembre 2019. en el Teatre del Lliceu de Barcelona, sed que recorría sus venas de descendiente del famoso tenor Viñas. Benefactor del Monasterio de Montserrat de tanto arraigo en la cultura catalana. Miembro de Numero de la Real Academia de Medicina de Cataluña. Doctor Honoris Causa de varias Universidades.

$\mathrm{Su}$ familia y en especial su querida esposa Leonor, fueron la razón de su vida.

Nos remece la tristeza de su pérdida, pero también el sentimiento de alegría, reconocimiento y gratitud de haber sido de alguna manera parte de su historia y sus logros. Ya mayor recibía con el afecto del profesor y casi como un padre a sus alumnos con quienes recordaba parte de su historia y revisaba con nostalgia y conformidad el camino recorrido.

Profesor Francesc Vilardell, su descanso es merecido. 